\title{
Morinda citrifolia: Amino Acid and Lipid Content of the Noni Fruit at Various Stages of Maturity
}

\author{
C. Lindsay and K. D. Golden* \\ Department of Basic Medical Sciences (Biochemistry section), University of the West Indies, Mona, \\ Kingston 7, Jamaica
}

Received 30 July 2011, accepted in final revised form 19 February 2012

\begin{abstract}
High performance liquid chromatography (HPLC) was used to determine the amino acid and fatty acid content of Morinda citrifolia (Noni). The amino acid content both free and total was determined at the mature green, mature ripe and fermented stage of the fruit. Most of the essential amino acids were detected as free amino acids (unhydrolysed sample) at the various stages of ripening, with threonine showing the highest value $(3.95 \pm 0.81 \mathrm{mg} / 100 \mathrm{~g})$ at the fermented stage and histidine showing the lowest value $(0.05 \pm 0.02 \mathrm{mg} / 100 \mathrm{~g})$ at the mature green stage. The essential amino acids with the exception of tryptophan (destroyed by acid hydrolysis) were also detected as total amino acids (hydrolyzed sample) albeit at much higher concentrations. Leucine showed the highest value $(94.21 \pm 18.85 \mathrm{mg} / 100 \mathrm{~g})$ at the mature ripe stage, whereas methionine the lowest value $(2.80 \pm 1.02 \mathrm{mg} / 100 \mathrm{~g})$ at the mature green stage. The fatty acid content of the Noni fruit was also determined at the green, ripe and fermented stages of ripening; with the short chain caprylic acid $(80.69 \pm 3.09$ $\mathrm{mg} / 100 \mathrm{~g}$ ) showing the highest value at the ripe stage. Significantly the essential fatty acids linolenic $(8.60 \pm 0.21 \mathrm{mg} / 100 \mathrm{~g})$ and linoleic $(50.57 \pm 0.72 \mathrm{mg} / 100 \mathrm{~g})$ were highest at the green stage. Also present in significant quantities were palmitic acid $(44.27 \pm 0.35 \mathrm{mg} / 100 \mathrm{~g})$ and stearic acid $(4.78 \pm 0.45 \mathrm{mg} / 100 \mathrm{~g})$ at the green stage. The amount of fatty acids decreased significantly at the fermented stage. Of the fatty acids detected at the fermented stage $79 \%$ of them were below $1.00 \mathrm{mg} / 100 \mathrm{~g}$ fresh weight of the fruit.
\end{abstract}

Keywords: Noni fruit; Amino acids; Fatty acids; HPLC.

(c) 2012 JSR Publications. ISSN: 2070-0237 (Print); 2070-0245 (Online). All rights reserved.

doi: http://dx.doi.org/10.3329/jsr.v4i2.8130 J. Sci. Res. 4 (2), 467-476 (2012)

\section{Introduction}

\subsection{History and medicinal properties}

Noni (Morinda citrifolia) is a small evergreen tree with shiny leaves which grows mainly in open coastal regions. The plant is native from the Indian Ocean but was later brought to Australia, Hawaii and the Caribbean by man. The yellowish-white ovoid lumpy-bodied fruit is composed of numerous, fused ripened ovaries, each derived from a separate white

\footnotetext{
*Corresponding author: kerith.golden@uwimona.edu.jm
} 
flower. The flesh is juicy and bitter and when ripe the fruit has a pronounced "rancid cheese" odour.

For more than 1000 years Noni has been domesticated and cultivated by populations throughout Polynesia where it is valued as a dye, medicine and food. The root has been employed for dyeing by the Australians and Indians; producing various shades of red, purple and yellow. The stem, bark, root, leaf and fruits are used traditionally by Hawaiians and Tahitians as medicines to treat a broad range of diseases including diabetes, hypertension and cancer. The fruit is also used topically for boils and other skin disorders [1].

Starting in 1990 the demand for noni escalated dramatically because of its cure-all reputation among Polynesians. Scientific investigation on noni started at least some 60 years ago but none of these actions have been corroborated by recent studies using more vigorous laboratory protocols. Although the fruit of noni have been used as a food, very few reports on the fruit are available. Compounds so far identified in the fruit include acetyl derivatives of asperuloside, glucose, caproic acid and caprylic acid [ 2].

The juice of the noni fruit have been shown to prolong the life span of mice implanted with Lewis lung carcinoma [3]. The same authors provided evidence showing that a partly identified polysaccharide acts by suppressing the growth of tumours by stimulating the immune system [4]. Recently they have isolated a polysaccharide rich substance with antitumour activity from the juice [5]. Rutin and asperlosidic acid along with a novel trisaccharide fatty acid ester were also isolated from the fruit [6]. Heinickle [7] reported that the noni fruit contains a natural component called proxeronine. Proxeronine is converted to xeronine (an alkaloid) by the enzyme proxeroninase, it is this alkaloid that is believed to be the active component of the noni fruit [7].

\subsection{Chromatographic analysis}

Amino acids are the building blocks of proteins which have several important biological functions including enzymatic activity, transport, hormonal activities and storage. Amino acids that are not derivatized do not chromatograph well, however upon derivatization they chromatograph fairly well. Amino acids have been analysed by HPLC by first forming 5-dimethylaminonaphthalenesulfonyl (dansyl); isoindoyl (OPA) or phenylisothiocyanate (PITC) derivatives that can be separated on reverse phase columns and detected at low concentrations. However, each reagent has it advantages and disadvantages and one must select for sensitivity, ease of execution, stability and specificity. Dansyl derivatives generally lack selectivity. They require long reaction time and high temperatures [8]. O-Phthaldehyde (OPA) is a fluorogenic derivatizing reagent that reacts rapidly at ambient temperature to form highly fluorescent isoindoles which are readily detected with a fluorescent detector. The disadvantage of this method is the lack of reactivity of OPA with secondary amino acids and the instability of the resulting fluorophores [9]. PITC although not as sensitive as OPA reacts with both primary and 
secondary amino acids to yield stable phenylthiocarbamyl (PTC) derivatives that can be detected by their uv absorption at $254 \mathrm{~nm}$ [10].

Fatty acids are the major components of lipids which function mainly as storage forms of energy and also form the structural component of membranes. The separation of fatty acid phenacyl derivatives by reverse-phase HPLC and uv detection has been widely and successfully employed [11]. This procedure is based on the chemical property of decreasing polarity with increasing chain length of the fatty acids and increasing polarity with an increase in the number of double bonds for unsaturated fatty acids.

This study will seek to further explore the chemical constituents of the noni fruit with particular focus on the nutritional value of the fruit with respect to its amino acid, and fatty acid content.

\section{Materials and Methods}

\subsection{Noni samples}

Noni (Morinda citrifolia) was obtained from trees on the compound of the University of the West Indies. Samples were analysed at the green, mature and fermented stage. For the fermented juice, the ripe fruit was left in a sealed container for 60 days, after which the fermented juice was collected.

\subsection{Reagents}

All chemicals were of reagent grade unless otherwise stated. Amino acids, fatty acids, triethanol amine (TEA), phenylisothiocianate(PITC), phenacyl bromide, HPLC-grade acetonitrile and sodium acetate were obtained from Sigma (St Louis, MO). Methanol, ethanol, diethyl ether, chloroform, isopropanol and hexane were obtained from Fisher Chemicals (Fair Lawn, NJ). Potassium hydroxide and sodium hydroxide were obtained from BDH (Poole, UK). Hydroxylamine hydrochloride was obtained from Koch-Light Laboratories (Colnbrook, Bucks, U.K.).

\subsection{Procedure for sample preparation: amino acids [unhydrolyzed (free)]}

Twenty gram of the pulp of the green or mature noni fruit was ground in $50 \mathrm{ml}$ of distilled water and filtered through cheese cloth. The filtrate was centrifuged for $12 \mathrm{~min}$ at 8, $000 \mathrm{x}$ g at $4{ }^{0} \mathrm{C}$ using a Beckman J-21 ultra centrifuge (Beckman Instruments, Fullerton, CA., USA). The supernatant $(55 \mathrm{ml})$ was removed and 5 volumes $(5 \mathrm{ml})$ of cold acetonitrile was added. The resulting solution was stored over-night in a refrigerator at $14{ }^{0} \mathrm{C}$. The solution was again centrifuged as above and the supernatant removed. The sample was placed in a $100 \mathrm{ml}$ round bottom flask and subjected to rotary evaporation $\left(90{ }^{0} \mathrm{C}\right)$ until appproximalety $2 \mathrm{ml}$ of the sample remained. The $2 \mathrm{ml}$ extract was made up to $15 \mathrm{ml}$ with $0.1 \mathrm{~N} \mathrm{HCl}$. 
Two stock solutions were prepared using $0.1 \mathrm{~N} \mathrm{HCl}$ as solvent: one contained a 3 $\mathrm{mg} / \mathrm{ml}$ solution of the twenty standard amino acids found in proteins plus norleucine as the internal standard (IS) at the same concentration; the other contained only norleucine at $3 \mathrm{mg} / \mathrm{ml}$. To a vial containing $5 \mathrm{ml}$ of the extract, $200 \mu \mathrm{l}$ of the internal standard solution $(3 \mathrm{mg} / \mathrm{ml})$ was added. For derivatization purposes $100 \mu \mathrm{l}$ of the extract containing the internal standard was used.

\subsection{Procedure for sample preparation: amino acids [hydrolyzed (total)]}

Crushed noni pulp ( $5 \mathrm{~g}$ ) of the green or mature noni and $15 \mathrm{ml}$ of $6 \mathrm{~N} \mathrm{HCl}$ were added to a screw cap pyrex vial for hydrolysis. Nitrogen was bubbled through the sample and the vial was sealed and left overnight in an oven at $110^{\circ} \mathrm{C}$. After $24 \mathrm{~h}$ the samples were removed, filtered and diluted to $40 \mathrm{ml}$ with distilled water. As described in the previous section $100 \mu \mathrm{l}$ of the extract containing the internal standard was used for derivatization purposes.

\subsection{Sample and standard amino acid derivatization}

The method used for the derivatization of the amino acids was a modification of the method outlined in [12].

\subsection{Procedure for sample preparation: fatty acids}

Noni pulp (100 g) from the green fruit or the ripe fruit was blended in $150 \mathrm{ml}$ of chloroform : isopropanol $(7: 11, \mathrm{v} / \mathrm{v})$ for $5 \mathrm{~min}$ at high speed. The slurry was placed in a beaker and left overnight in a refrigerator at $14{ }^{\circ} \mathrm{C}$. The extract was then filtered under mild vacuum using a Buchner funnel and Whatman No 1 filter paper (Whatman International Ltd., Kent, U.K.). The filtrate was reduced to approximately $10 \mathrm{ml}$ by rotary evaporation. The reduced volume was placed in a screw cap vial and saponified by adding $4 \mathrm{ml}$ of $0.5 \mathrm{~N} \mathrm{KOH}$ in ethanol and heated in a water bath for $2 \mathrm{~h}$ at $95{ }^{0} \mathrm{C}$. Upon cooling the content of the vial was extracted three times with $10 \mathrm{ml}$ of hexane. The pooled extract (35 $\mathrm{ml}$ ) was reduced to approximately $5 \mathrm{ml}$ via rotary evaporation.

For the fermented fruit; ripe fruits were allowed to ferment for 10 days, after which the fermented juice was collected. An aliquot $(10 \mathrm{ml})$ of the fermented juice was saponified, extracted three times with hexane, pooled $(35 \mathrm{ml})$ and evaporated to $5 \mathrm{ml}$ as mentioned in the previous paragraph.

\subsection{Sample and standard fatty acid derivatization}

Fatty acids were derivatized by a modification of the method outlined in ref. [13].

\subsection{Spiked samples for percentage recovery}

To determine the efficiency of the extraction procedure, noni samples were spiked with a known amount (10 mg each) of the standard amino acids or the standard fatty acids and 
carried through the extraction and derivatization processes as previously described. Percentage recovery was obtained by comparing the amount that was found in the sample with the amount that was added; quantitation was based on the internal standard method as described by Golden and Williams [14].

\subsection{HPLC apparatus for amino acid analysis}

The HPLC equipment consisted of a chromatographic system (Beckman system Gold Nouveau, Fullerton, CA., USA) comprised of dual pumps, a solvent module (Model 126), a $20 \mu$ l Rheodyne ( Rohnert Park, CA., USA) injection loop, a UV-Visible detector (Model 168) and an autosampler (Model 508) all linked to a computer running Gold Nouveau software. Amino acids were separated using a 5- $\mu \mathrm{m}$ Spherisorb (Suppelco Inc, Bellefonte, PA., USA) ODS2 column (4.6 x $250 \mathrm{~mm})$. Absorbance was measured at $254 \mathrm{~nm}$. All samples $(20 \mu \mathrm{l})$ were injected using the autosampler.

\subsubsection{HPLC apparatus for fatty acid analysis}

Analyses was carried out using an Aglient Series Chromatograph (Agilent Technologies Inc, Santa Clara, CA., USA) equipped with an Aglient 1100 series quaternary pump and an Aglient 1100 series variable wave length detector and a Trialthon auto sampler (Type 900). Fatty acids were separated using a 5- $\mu \mathrm{m}$ Zorbax SB-C18 (Suppelco Inc, Bellefonte, PA., USA) column (4.6 x $250 \mathrm{~mm})$. Absorbance was measured at $241 \mathrm{~nm}$. All samples $(20 \mu \mathrm{l})$ were injected using the autosampler.

\subsubsection{Time programme for amino acids analysis}

Chromatography was carried out at ambient temperature using a gradient elution as follows: Eluant A was an aqueous buffer consisting of 0.05M ammonium acetate. Eluant B consisted of 0.01M ammonium acetate in acetonitrile - methanol - water (44:10:46, v/v). Both eluants were adjusted to $\mathrm{pH} 6.8$ with phosphoric acid.

In the gradient program employed, the pumps were operated with $0 \% \mathrm{~B}$ initially for 2 $\mathrm{min}$ at a rate of $1 \mathrm{ml} / \mathrm{min}$. This was increased to $50 \% \mathrm{~B}$ in a period of $30 \mathrm{~min}$, after which there was a further increase from $50 \%$ B to $75 \%$ B in 5 min. $75 \%$ B was maintained for 5 min and reduced to $0 \% \mathrm{~B}$ in $10 \mathrm{~min}$.

\subsubsection{Time programme for fatty acids analysis}

Fatty acids were separated by HPLC at ambient temperature using gradient elution. Eluent A was acetonitrile-water $(67: 33, \mathrm{v} / \mathrm{v})$ and eluent B was acetonitrile. The pumps were operated initially with $100 \%$ B at time $0.10 \mathrm{~min}$, and was held at $100 \%$ B for $20 \mathrm{~min}$. Then $100 \%$ B was reduced to $0 \% \mathrm{~B}$ in $10 \mathrm{~min}$. The flow rate for the entire run was $2 \mathrm{ml} /$ min. 


\section{Results and Discussion}

The amount of each component in the noni fruit was quantified using the internal standard method as outlined in [14] and [15]. Identification of each component at the various stages of ripening was achieved by comparing the Relative Retention Time (RRT) of the standard compounds to that of the sample. The RRT is the ratio of the retention time of the standard compounds to that of the IS. Although the retention time can vary during the course of different analysis, the RRT remains relatively constant; as is evident in Tables I, 2 and 3.

Table 1. Free amino acid content of noni fruit, at different stages of ripening.

\begin{tabular}{|c|c|c|c|c|c|}
\hline Amino acid & $\begin{array}{l}\mathrm{RRT}^{+} \\
\text {standards }\end{array}$ & $\begin{array}{l}\mathrm{RRT}^{++} \\
\text {sample }\end{array}$ & $\begin{array}{l}\text { Mature green fruit } \\
(\mathrm{mg} / 100 \mathrm{~g})^{\S}\end{array}$ & $\begin{array}{l}\text { Mature ripe fruit } \\
\text { (mg/100g) }\end{array}$ & $\begin{array}{l}\text { Fermented fruit } \\
(\mathrm{mg} / 100 \mathrm{~g})\end{array}$ \\
\hline Aspartic acid & 0.09 & 0.10 & $8.22 \pm 0.61^{* *}$ & $7.02 \pm 1.01$ & $15.36 \pm 0.47$ \\
\hline Glumatic acid & 0.12 & 0.12 & $4.25 \pm 0.31$ & $4.05 \pm 0.46$ & $9.92 \pm 1.08$ \\
\hline Hydroxyproline & 0.29 & 0.29 & $0.06 \pm 0.01$ & $0.20 \pm 0.06$ & $0.37 \pm 0.06$ \\
\hline Serine & 0.34 & 0.35 & $2.48 \pm 0.23$ & $4.57 \pm 0.56$ & $10.21 \pm 1.15$ \\
\hline Glycine & 0.38 & 0.39 & $0.27 \pm 0.02$ & $0.74 \pm 0.09$ & $2.93 \pm 0.32$ \\
\hline Asparagine & 0.42 & 0.42 & $19.00 \pm 2.60$ & $20.67 \pm 3.96$ & $107.22 \pm 12.41$ \\
\hline Glutamine & 0.47 & 0.47 & $0.72 \pm 0.11$ & $5.92 \pm 1.03$ & $8.57 \pm 1.58$ \\
\hline Threonine* & 0.56 & 0.56 & $0.45 \pm 0.05$ & $1.46 \pm 0.29$ & $3.95 \pm 0.81$ \\
\hline Alanine & 0.58 & 0.58 & $2.96 \pm 0.43$ & $15.00 \pm 3.14$ & $44.73 \pm 4.20$ \\
\hline Histidine* & 0.63 & 0.64 & $0.05 \pm 0.02$ & $0.64 \pm 0.10$ & $2.94 \pm 0.43$ \\
\hline Proline & 0.66 & 0.66 & $1.00 \pm 0.10$ & $12.52 \pm 2.11$ & $9.73 \pm 0.75$ \\
\hline Arginine & 0.78 & 0.78 & $0.19 \pm 0.05$ & $1.39 \pm 0.30$ & $5.78 \pm 0.58$ \\
\hline Tyrosine & 0.84 & 0.84 & $0.03 \pm 0.01$ & $1.11 \pm 0.26$ & $3.74 \pm 0.19$ \\
\hline Valine* & 0.85 & 0.85 & $0.58 \pm 0.07$ & $0.92 \pm 0.18$ & $3.14 \pm 0.35$ \\
\hline Methionine* & 0.87 & 0.87 & $0.17 \pm 0.06$ & $0.47 \pm 0.09$ & $1.56 \pm 0.18$ \\
\hline Cysteine & 0.91 & 0.91 & $2.32 \pm 0.39$ & $2.02 \pm 0.62$ & $0.92 \pm 0.22$ \\
\hline Isoleucine* & 0.96 & 0.96 & $0.17 \pm 0.04$ & $0.54 \pm 0.13$ & $1.71 \pm 0.21$ \\
\hline Leucine* & 0.97 & 0.97 & $0.78 \pm 0.09$ & $1.28 \pm 0.29$ & $3.93 \pm 0.50$ \\
\hline Phenylalanine* & 1.05 & 1.06 & $0.22 \pm 0.04$ & $1.35 \pm 0.26$ & $3.72 \pm 0.64$ \\
\hline Tryptophan* & 1.09 & 1.09 & $0.06 \pm 0.01$ & $0.27 \pm 0.03$ & $0.28 \pm 0.05$ \\
\hline Lysine* & 1.15 & 1.16 & $0.35 \pm 0.03$ & $1.33 \pm 0.12$ & $2.89 \pm 0.20$ \\
\hline Norleucine (IS) & 1.00 & & & & \\
\hline
\end{tabular}

${ }^{* *}$ Mean; ${ }^{ \pm}$standard error; ${ }^{*}$ Essential amino acids; $\quad{ }^{+}$RRT of standard amino acids;

${ }^{++}$RRT of the amino acids found in the sample (mature ripe fruit). ${ }^{\S}$ wet weight of fruit.

Table 1 shows the free amino acid content of the noni fruit at the mature green, mature ripe and fermented stage of ripening. All of the essential amino acids were detected as free amino acids at the various stages of ripening, with threonine showing the highest 
value (3.95 $\pm 0.81 \mathrm{mg} / 100 \mathrm{~g}$ ) at the fermented stage and histidine showing the lowest value $(0.05 \pm 0.02 \mathrm{mg} / 100 \mathrm{~g})$ at the mature green stage. With respect to the nonessential amino acids asparagine was detected in the highest quantity $(107.22 \pm 12.41 \mathrm{mg} / 100 \mathrm{~g})$ at the fermented stage and tyrosine in the lowest quantity $(0.03 \pm 0.01 \mathrm{mg} / 100 \mathrm{~g})$ at the mature green stage.

Table 2 shows the total amino acid content of the noni fruit at the different stages of ripening. There was a significant increase in the amount of amino acids (both essential and non-essential) detected in the hydrolysed sample (total amino acid). This is expected as hydrolysis of the many polypeptides present would increase the pool of amino acids. Significant increases were shown for aspartic acid and glutamic acid at all stages of ripening, this is not surprising as asparagine and glutamine upon acid hydrolysis are converted to aspartic acid and glutamic acid, respectively. Table 1 shows aspartic acid at $7.02 \pm 1.01 \mathrm{mg} / 100 \mathrm{~g}$ at the mature green stage for the free amino acid , compared to 110.06 $\pm 28.0 \mathrm{mg} / 100 \mathrm{~g}$ at the mature green stage for the total amino acid (Table 2); a 15.67 fold increase. Tryptophan was not detected in the hydrolysed sample due to decomposition upon acid hydrolysis.

Table 2. Total amino acid content of the noni fruit, at different stages of ripening.

\begin{tabular}{|c|c|c|c|c|c|}
\hline Amino acid & $\begin{array}{l}\mathrm{RRT}^{+} \\
\text {Standards }\end{array}$ & $\begin{array}{l}\mathrm{RRT}^{++} \\
\text {Sample }\end{array}$ & $\begin{array}{l}\text { Mature green fruit } \\
(\mathrm{mg} / 100 \mathrm{~g})^{\S}\end{array}$ & $\begin{array}{l}\text { Mature ripe fruit } \\
\text { (mg/100g) }\end{array}$ & $\begin{array}{l}\text { Fermented fruit } \\
(\mathrm{mg} / 100 \mathrm{~g})\end{array}$ \\
\hline Aspartic acid & 0.09 & 0.09 & $39.81 \pm 9.02^{* *}$ & $110.06 \pm 28.0$ & $116.33 \pm 30.72$ \\
\hline Glumatic acid & 0.12 & 0.12 & $48.09 \pm 13.67$ & $69.87 \pm 20.1$ & $66.23 \pm 17.9$ \\
\hline Hydroxyproline & 0.29 & 0.29 & $5.25 \pm 1.04$ & nd & $2.47 \pm 0.83$ \\
\hline Serine & 0.34 & 0.34 & $33.28 \pm 6.12$ & $26.73 \pm 7.44$ & $34.88 \pm 5.16$ \\
\hline Glycine & 0.38 & 0.38 & $39.47 \pm 5.92$ & $37.70 \pm 10.68$ & $37.97 \pm 3.70$ \\
\hline Asparagine & 0.42 & - & nd & nd & nd \\
\hline Glutamine & 0.47 & - & nd & nd & nd \\
\hline Threonine* & 0.56 & 0.56 & $32.85 \pm 4.50$ & $41.70 \pm 4.86$ & $29.95 \pm 4.52$ \\
\hline Alanine & 0.58 & 0.58 & $43.65 \pm 4.92$ & $59.22 \pm 11.66$ & $76.23 \pm 15.49$ \\
\hline Histidine* & 0.63 & 0.64 & $11.88 \pm 2.86$ & nd & nd \\
\hline Proline & 0.66 & 0.65 & $44.29 \pm 9.64$ & $68.19 \pm 6.45$ & $51.04 \pm 2.94$ \\
\hline Arginine & 0.78 & 0.77 & $48.79 \pm 8.56$ & $56.50 \pm 14.38$ & $41.15 \pm 6.29$ \\
\hline Tyrosine & 0.84 & 0.84 & $20.32 \pm 5.46$ & $26.19 \pm 5.19$ & $29.99 \pm 12.28$ \\
\hline Valine* & 0.85 & 0.85 & $35.56 \pm 7.08$ & $27.78 \pm 9.81$ & $30.11 \pm 7.11$ \\
\hline Methionine* & 0.87 & 0.87 & $2.80 \pm 1.02$ & $3.00 \pm 0.98$ & $6.26 \pm 1.46$ \\
\hline Cysteine & 0.91 & 0.91 & $9.48 \pm 2.24$ & nd & nd \\
\hline Leucine* & 0.96 & 0.96 & $64.57 \pm 4.66$ & $94.21 \pm 18.85$ & $72.15 \pm 18.37$ \\
\hline Isoleucine* & 0.97 & 0.97 & $30.36 \pm 4.91$ & $25.32 \pm 5.50$ & $20.18 \pm 4.90$ \\
\hline Phenylalanine* & 1.05 & 1.05 & $24.97 \pm 3.11$ & $8.83 \pm 3.46$ & $46.07 \pm 10.45$ \\
\hline Tryptophan* & 1.09 & - & nd & nd & nd \\
\hline Lysine* & 1.15 & 1.15 & $25.84 \pm 5.62$ & nd & $21.07 \pm 2.83$ \\
\hline Norleucine (IS) & 1.00 & & & & \\
\hline
\end{tabular}

\footnotetext{
** Mean \pm standard error; ${ }^{*}$ Essential amino acids; ${ }^{+}$RRT of standard amino acids; ${ }^{++}$RRT of the amino acids
} found in the sample (mature green fruit); ${ }^{\S}$ Wet weight of fruit. nd = not detected. 
Table 3. Fatty acid content of noni fruit at different stages of ripening.

\begin{tabular}{llllll}
\hline Fatty acid & $\begin{array}{l}\mathrm{RRT}^{+} \\
(\text {standards })\end{array}$ & $\begin{array}{l}\mathrm{RRT}^{++} \\
(\mathrm{sample})\end{array}$ & $\begin{array}{l}\text { Mature green } \\
(\mathrm{mg} / 100 \mathrm{~g})^{\S}\end{array}$ & $\begin{array}{l}\text { Mature Ripe } \\
(\mathrm{mg} / 100 \mathrm{~g})\end{array}$ & $\begin{array}{l}\text { Fermented } \\
(\mathrm{mg} / 100 \mathrm{~g})\end{array}$ \\
\hline Caprioc-C6 & 0.23 & 0.23 & $2.30 \pm 0.40^{* *}$ & $16.21 \pm 1.08$ & $6.00 \pm 0.51$ \\
Heptanoic-C7 & 0.28 & 0.28 & $\mathrm{nd}$ & $\mathrm{nd}$ & $0.51 \pm 0.12$ \\
Caprylic-C8 & 0.33 & 0.33 & $0.53 \pm 0.07$ & $80.69 \pm 3.09$ & $9.52 \pm 0.41$ \\
Nonanoic-C9 & 0.40 & 0.39 & $0.07 \pm 0.05$ & $1.07 \pm 0.19$ & $0.16 \pm 0.04$ \\
Capric-C10 & 0.46 & 0.46 & $1.90 \pm 0.49$ & $4.47 \pm 0.12$ & $0.14 \pm 0.01$ \\
Undecanoic-C11 & 0.52 & 0.50 & nd & $1.14 \pm 0.09$ & $0.05 \pm 0.01$ \\
Lauric-C12 & 0.58 & 0.58 & $0.98 \pm 0.33$ & $0.38 \pm 0.07$ & $0.07 \pm 0.02$ \\
Linolenic-C18:3 & 0.64 & 0.64 & $8.60 \pm 0.21$ & $2.90 \pm 0.04$ & $0.12 \pm 0.02$ \\
Myristic-C14 & 0.68 & 0.68 & $0.75 \pm 0.04$ & $0.34 \pm 0.03$ & $0.14 \pm 0.03$ \\
Linoleic-C18:2 & 0.70 & 0.70 & $50.57 \pm 0.72$ & $6.71 \pm 0.23$ & $0.23 \pm 0.04$ \\
Pentadecanoic-C15 & 0.72 & 0.72 & $0.62 \pm 0.06$ & $1.03 \pm 0.14$ & $0.22 \pm 0.02$ \\
Palmitic-C16 & 0.77 & 0.77 & $44.27 \pm 0.35$ & $31.77 \pm 0.45$ & $1.82 \pm 0.10$ \\
Heptadecanoic-C17 & 0.83 & 0.83 & $1.31 \pm 0.20$ & $1.35 \pm 0.30$ & $0.17 \pm 0.03$ \\
Stearic-C18 & 0.90 & 0.90 & $4.78 \pm 0.45$ & $2.78 \pm 0.46$ & $0.38 \pm 0.06$ \\
Nonadecanoic-C19 & 1.00 & & & & \\
\hline
\end{tabular}

** Mean \pm standard error; ${ }^{*}$ Essential fatty acids; ${ }^{+}$RRT of standard fatty acids;

${ }^{++} \mathrm{RRT}$ of the fatty acids found in the sample; ${ }^{\S}$ Wet weight of fruit.

Table 3 shows the fatty acid profile of the noni fruit at two ripening stages (mature green and ripe) and at the fermented stage. It is noteworthy that the omega-3 (linolenic acid) and omega-6 (linoleic acid) fatty acids are present in the mature green noni at concentrations of $8.60 \pm 0.21 \mathrm{mg} / 100 \mathrm{~g}$ and $50.57 \pm 0.72 \mathrm{mg} / 100 \mathrm{~g}$ respectively. The omega3 and omega- 6 fatty acids are considered essential fatty acids; they cannot be synthesized by humans and must be provided in the diet. Linoleic acid is needed as the precursor of arachidonic acid, which in turn is the precursor of prostaglandins and thromboxanes [16]. Also present at the mature green stage in significant amount is palmitic acid $(44.27 \pm 0.35$ $\mathrm{mg} / 100 \mathrm{~g})$.

Upon ripening the noni fruit becomes very pungent; this is probably due to the presence of the short chain fatty acids caproic acid $(16.21 \pm 1.08 \mathrm{mg} / 100 \mathrm{~g})$ and caprylic acid $(80.69 \pm 3.09 \mathrm{mg} / 100 \mathrm{~g})$.These fatty acids are known for their pungency. At the fermented stage there was a significant decline in the concentration of all the fatty acids, seventy nine percent (79\%) of the fatty acids detected at the fermented stage fell below $1.00 \mathrm{mg} / 100 \mathrm{~g}$ fresh weight of the fruit.

The efficiency of the extraction procedure for both the amino acids and fatty acids was good; as the percentage recovery for the $\mathrm{C} 6 \rightarrow \mathrm{C} 12$ fatty acids was $90 \%$, while that of the C14 $\rightarrow$ C18 was 95\%. Where the amino acids were concerned, Asp, Glu, Hypro, Ser, Gly, Asn, Gln, Thr, Ala, His and Pro gave a percentage recovery of $80 \%$, while Arg, Tyr, Val, 
Met, Cys, Ileu, Leu, Phe, Trp, and Lys gave percentage recoveries that were greater than $95 \%$.

\section{Conclusion}

It is evident that the noni fruit is of nutritional value, It contains all the essential amino acids plus the omega- 3 and omega- 6 fatty acids, similar findings are reported in [17] and [18]. Where percentage weight of total fatty acids are concerned (Table 4), noni has a high percentage weight of the omega -3 fatty acid (44\%) which compares well with corn oil (58\%) and soybean oil (54\%). Its Omega-6 content (7.7\%) is superior to corn oil (1\%) and soybean oil (7\%) (Table 4).

Table 4. Fatty acid composition of noni fruit, canola oil, corn oil and soybean oil.

\begin{tabular}{lllllllll}
\hline Plant & Capric & Lauric & Myristic & Palmitic & Stearic & Oleic & Linoleic & Linolenic \\
Material & C10:0 & C12:0 & C14:0 & C16:0 & C18:0 & C18:1 & C18:2 & C18:3 \\
\hline Noni fruit & $1.7^{+}$ & 0.85 & 0.63 & 38 & 4.3 & - & 44 & 7.7 \\
*Canola oil & - & - & - & $4^{+}$ & 2 & 62 & 22 & 10 \\
*Corn oil & & & & $11^{+}$ & 2 & 28 & 58 & 1 \\
*Soybean oil & & & & $11^{+}$ & 4 & 24 & 54 & 7 \\
\hline
\end{tabular}

${ }^{+}$Values represent percentage weight of total fatty acids; *Ref. [19].

\section{Acknowledgement}

We are grateful to Research and Publications of the University of the West Indies, Mona, for supporting this study.

\section{References}

1. F. J. Morton, Economic Botany 46, 241 (1992). http://dx.doi.org/10.1007/BF02866623

2. O. Levand and H. Larson, Planta. Med. 36, 186 (1979). http://dx.doi.org/10.1055/s-0028-1097264

3. A. Hirazumi, E. Furusawa, S. C. Chou, and Y. Hokama, Proc. West. Pharmacol. Soc. 37, 145 (1994). PMid:7984648

4. A. Hirazumi, E. Furusawa, S. C. Chou, and Y. Hokama, Proc. West. Pharmacol. Soc. 39, 25 (1996).

5. A. Hirazumi and E. Furusawa, Phytother. Res. 13, 380 (1999). http://dx.doi.org/10.1002/(SICI)1099-1573(199908/09)13:5<380::AID-PTR463>3.0.CO;2-M

6. M. F. Wang, H. Kikuzaki, and K. J. Csiszar. Agri. Food. Chem. 47, 4880 (1999). http://dx.doi.org/10.1021/jf990608v

7. R. M. Heinecke, Bull. Nat. Trop. Botan. Garden 15, 10 (1985).

8. C. Debarber, J. A. Prieto, and C. Collar, Cereal Chem. 66, 283 (1990).

9. L. Limieux, R. Puchades, and R. E. Simrad, J. Food Sci. 55, 1552 (1990). http://dx.doi.org/10.1111/j.1365-2621.1990.tb03566.x

10. V. Fierabracci, P. Masiello, M. Novelli, and E. Bergamini, J. Chromatogr. 570, 285 (1991).

11. I. Zaitseva, M. Ajmal, and E. Cersosimo, J. Chromatogr B 727, 15 (1999). 


\section{Morinda citrifolia}

http://dx.doi.org/10.1016/S0378-4347(99)00051-1

12. M. J. Gonzalez-Castro, J. Lopez-Hernandez, J. Simal-Lozano, and M. J. Oruna-Concha, J. Chromatogr. Sci. 35, 181 (1997).

13. R. F. Borch, Anal. Chem. 47, 2437 (1975). http://dx.doi.org/10.1021/ac60364a037

14. K. D. Golden and O. J. Williams, J. Chromatogr. Sci. 39, 243 (2001).

15. K. D. Golden, O. J. Williams, and Y. Bailey-Shaw, J Chromatogr. Sci. 40, 441 (2002).

16. A. L. Lehninger, Principles of Biochemistry (Worth Publishers, New York, 1982) pp. 758-759.

17. B. J. West, S. Deng, and C. J. Jensen, Food Res. Inter. 44, 2295 (2011). http://dx.doi.org/10.1016/j.foodres.2010.09.038

18. K. Kamiya, Y. Tanaka, H. Endang, M. Umar, and T. Satake, J. Agric. Food Chem. 52, 5843 (2004). http://dx.doi.org/10.1021/jf040114k

19. Website: http://www.connectworld.net/whc/images/chart.pdf 